University of Nebraska - Lincoln

DigitalCommons@University of Nebraska - Lincoln

\title{
Liposome-induced complement activation and related cardiopulmonary distress in pigs: factors promoting reactogenicity of Doxil and AmBisome
}

\author{
János Szebeni \\ Semmelweis University of Medical Sciences, jszebeni2@gmail.com \\ Péter Bedőcs \\ Uniformed Services University of Health Sciences \\ Zoltán Rozsnyay \\ Seroscience Ltd. \\ Zsóka Weiszhár \\ Seroscience $L t d$. \\ Rudolf Urbanics \\ Seroscience $L t d$. \\ See next page for additional authors \\ Follow this and additional works at: https://digitalcommons.unl.edu/usuhs \\ Part of the Medicine and Health Sciences Commons
}

Szebeni, János; Bedőcs, Péter; Rozsnyay, Zoltán; Weiszhár, Zsóka; Urbanics, Rudolf; Rosivall, László; Cohen, Rivka; Garbuzenko, Olga; Báthori, György; Tóth, Miklós; Bünger, Rolf; and Barenholz, Yechezkel, "Liposome-induced complement activation and related cardiopulmonary distress in pigs: factors promoting reactogenicity of Doxil and AmBisome" (2011). Uniformed Services University of the Health Sciences. 75.

https://digitalcommons.unl.edu/usuhs/75

This Article is brought to you for free and open access by the U.S. Department of Defense at DigitalCommons@University of Nebraska - Lincoln. It has been accepted for inclusion in Uniformed Services University of the Health Sciences by an authorized administrator of DigitalCommons@University of Nebraska Lincoln. 


\section{Authors}

János Szebeni, Péter Bedőcs, Zoltán Rozsnyay, Zsóka Weiszhár, Rudolf Urbanics, László Rosivall, Rivka Cohen, Olga Garbuzenko, György Báthori, Miklós Tóth, Rolf Bünger, and Yechezkel Barenholz 


\title{
Liposome-induced complement activation and related cardiopulmonary distress in pigs: factors promoting reactogenicity of Doxil and AmBisome
} János Szebeni, $\mathrm{MD}, \mathrm{PhD}, \mathrm{DSc}^{\mathrm{a}, *, 1}$, Péter Bedőcs, $\mathrm{MD}^{\mathrm{b}, 1}$, Zoltán Rozsnyay, $\mathrm{MSc}, \mathrm{PhD}^{\mathrm{c}}$, Zsóka Weiszhár, $\mathrm{MSc}^{\mathrm{c}}$, Rudolf Urbanics, $\mathrm{MD}, \mathrm{PhD}^{\mathrm{c}}$, László Rosivall, $\mathrm{MD}, \mathrm{PhD}, \mathrm{DSc}^{\mathrm{d}}$, Rivka Cohen, $\mathrm{PhD}^{\mathrm{e}}$, Olga Garbuzenko, $\mathrm{PhD}^{\mathrm{e}}$, György Báthori, $\mathrm{MD}, \mathrm{PhD}^{\mathrm{f}}$, Miklós Tóth, $\mathrm{MD}, \mathrm{PhD}, \mathrm{DSc}^{\mathrm{g}}$, Rolf Bünger, $\mathrm{MD}, \mathrm{PhD}^{\mathrm{h}}$, Yechezkel Barenholz, $\mathrm{PhD}^{\mathrm{e}}$

${ }^{\mathrm{a} N a n o m e d i c i n e ~ R e s e a r c h ~ a n d ~ E d u c a t i o n ~ C e n t e r, ~ B a y ~ Z o l t a n ~ F o u n d a t i o n ~ f o r ~ A p p l i e d ~ R e s e a r c h, ~ S e m m e l w e i s ~ U n i v e r s i t y, ~}$ and Department of Pathophysiology, Miskolc University, Faculty of Health, and Seroscience Ltd., Budapest, Hungary

' Semmelweis University, Budapest, Hungary, and Department of Anatomy, Physiology and Cell Biology, Uniformed Services University of Health Sciences, Bethesda, Maryland, USA 'Seroscience Ltd., Budapest, Hungary

${ }^{\mathrm{d}}$ Department of Pathophysiology, Faculty of Medicine, Semmelweis University, Hungarian Academy of Sciences-Semmelweis University, Nephrology Research Group, Budapest, Hungary

${ }^{\mathrm{e}}$ Laboratory of Membrane and Liposome Research, Hebrew University-Hadassah Medical School, Jerusalem, Israel

${ }^{\mathrm{f}}$ Nanomedicine Research and Education Center, Bay Zoltan Foundation for Applied Research, and Semmelweis University, Budapest, Hungary ${ }^{g}$ Department of Health Science and Sport Medicine, Faculty of Physical Education and Sport Science, Semmelweis Medical University, Budapest, Hungary ${ }^{\mathrm{h}}$ Department of Anatomy, Physiology and Cell Biology, Uniformed Services University of Health Sciences, Bethesda, Maryland, USA

Received 22 September 2010; accepted 4 June 2011

\begin{abstract}
Hypersensitivity reactions to liposomal drugs, often observed with Doxil and AmBisome, can arise from activation of the complement (C) system by phospholipid bilayers. To understand the mechanism of this adverse immune reaction called C activation-related pseudoallergy (CARPA), we analyzed the relationship among liposome features, C activation in human serum in vitro, and liposome-induced cardiovascular distress in pigs, a model for human CARPA. Among the structural variables (surface charge, presence of saturated, unsaturated, and PEGylated phospholipids, and cisplatin vs. doxorubicin inside liposomes), high negative surface charge and the presence of doxorubicin were significant contributors to reactogenicity both in vitro and in vivo. Morphological analysis suggested that the effect of doxorubicin might be indirect, via distorting the sphericity of liposomes and, if leaked, causing aggregation. The parallelism among $\mathrm{C}$ activation, cardiopulmonary reactions in pigs, and high rate of hypersensitivity reactions to Doxil and AmBisome in humans strengthens the utility of the applied tests in predicting the risk of CARPA.
\end{abstract}

(C) 2011 Elsevier Inc. All rights reserved.

Key words: Nanomedicines; Cancer chemotherapy; Drug targeting; Immune toxicity; Infusion reactions

Over the past two decades numerous liposome formulations have reached advanced clinical trials or approvals as medicines. ${ }^{1-5}$ Among these, liposomal doxorubicin (Doxil,

Financial support from the following organizations is gratefully acknowledged: The Barenholz Fund; Nanomedi and Carpa777 grants from the National Office of Research and Technology of Hungary; FP7 grant "Anticarb”, USUHS RO70LO; TÁMOP-4.2.1/B-09/1/KMR for Semmelweis University and TAMOP-4.2.1.B-10/2/KONV-2010-0001 for Miskolc University, with support by the European Union, co-financed by the European Social Fund.

*Corresponding author: Nanomedicine Research and Education Center, Semmelweis University, Budapest, 1089 Nagyvárad tér 4, Hungary.

E-mail address: jszebeni2@gmail.com (J. Szebeni).

${ }^{1}$ Equal contributors.
Caelyx, Ben Venue Laboratories, Inc. Bedford, Ohio, for Centocor Ortho Biotech Products, LP Raritan, New Jersey) ${ }^{6,7}$ and liposomal amphotericin B (AmBisome, Gilead, Astellas Pharma US, Inc. North Deerfield, Illinois $)^{8,9}$ are the best known, most widely used products. Besides their therapeutic benefits, however, these and many other liposomal drugs carry an increased risk for hypersensitivity reactions (HSRs), also known as infusion reactions. Depending on premedication and numerous patient and product-related factors, the frequency of HSRs is in the $2-30 \%$ range, for example $\sim 10 \%$ with Doxil ${ }^{10}$ and $\sim 30 \%$ with Ambisome. ${ }^{11}$ The reactions are mostly minor and transient; however, life-threatening or even deadly reactions can happen occasionally in a hypersensitive individual. The latter 
Table 1

Vesicle structural factors analyzed for complement reactogenicity

\begin{tabular}{|c|c|c|}
\hline \multicolumn{2}{|l|}{ Variables } & \multirow{2}{*}{$\begin{array}{l}\text { Character or range } \\
0.3-5.0 \%\end{array}$} \\
\hline Surface & Density & \\
\hline PEG & Chain size & $0.35,2$, and $12 \mathrm{kDa}$ or none \\
\hline & $\begin{array}{l}\text { Lipid anchor } \\
\text { charge }\end{array}$ & $\begin{array}{l}\text { Phosphatidylethanolamine } \\
\text { vs. distearoyl or } \\
\text { distearoylglycerol oxycarbonyl } \\
\text { 3-amino-1,2-propandiol; (intravenous) }\end{array}$ \\
\hline \multirow{4}{*}{$\begin{array}{l}\text { Vesicle } \\
\text { features }\end{array}$} & $\begin{array}{l}\text { Type of } \\
\text { phospholipid assembly }\end{array}$ & $\begin{array}{l}\text { Micelle, } \\
\text { bilayer vesicle }\end{array}$ \\
\hline & Payload & $\begin{array}{l}\text { Doxorubicin, cisplatin, } \\
\text { amphotericin B, none (PBS) }\end{array}$ \\
\hline & $\begin{array}{l}\text { Phospholipid } \\
\text { composition }\end{array}$ & HSPC, HSPG, EPC, DSPE \\
\hline & Surface charge & $\begin{array}{l}\text { Zeta potential } \\
\text { (from }-60 \text { to }+1 \mathrm{mV} \text { ) }\end{array}$ \\
\hline
\end{tabular}

fact lends considerable clinical relevance to the phenomenon, particularly in patients with a background of atopic constitution and cardiovascular disease.

Previous studies highlighted the non-IgE-mediated, anaphylactoid (pseudoallergic) nature of liposome reactions, pointing to activation of the complement (C) system as probably the underlying cause. ${ }^{12-16}$ Hence the name, $\mathrm{C}$ activation-related pseudoallergy (CARPA). ${ }^{15,16}$ It was also established earlier that multilamellarity, large size, and the presence of very high amounts $(71 \%)$ of cholesterol in the bilayer membrane ${ }^{13}$ are properties that promote $\mathrm{C}$ activation and CARPA. Most recently, the causal role in $\mathrm{C}$ activation of acidic phosphate groups on polyethylene glycol-conjugated (PEGylated) phosphatidylethanolamine (PE) has been demonstrated. ${ }^{17}$ Nevertheless, liposomes are defined by a large number of chemical and structural variables whose impacts on $\mathrm{C}$ reactivity and CARPA have not been explored to date.

The goal of the present study was to analyze the effects of liposomal surface modifications and internal content on $\mathrm{C}$ reactivity and CARPA, using Doxil and AmBisome as known reactogenic drug controls. Complement activation was assessed by measuring the formation of S-protein-bound terminal $\mathrm{C}$ complex (membrane attack complex) (SC5b-9) in human serum, whereas CARPA was evaluated by measuring liposome-induced cardiopulmonary distress in pigs. The particular liposome variables studied are summarized in Table 1.

\section{Methods}

\section{Materials}

Dimyristoyl phosphatidylcholine (DMPC), dimyristoyl phosphatidylglycerol (DMPG), cholesterol (Chol), and egg yolk phosphatidylcholine (EPC) were purchased from Avanti Polar Lipids Inc. (Alabaster, Alabama). Fully hydrogenated soy phosphatidylcholine (HSPC) and soy PG (HSPG) were from Lipoid Inc. (Ludwigshafen, Germany). All lipids had a purity of $\geq 97 \%$. Zymosan was from Sigma Chemical Co. (St. Louis, Missouri). Commercial Doxil (Ben Venue Laboratories, Inc.), doxorubicin (TEVA Pharmaceuticals, Petach Tikva, Israel), and
AmBisome (Gilead, Astellas Pharma US, Inc.) were obtained from local pharmacies. The negatively charged $N$-carbamyl-poly (ethylene glycol methyl ether)-1,2-distearoyl-sn-glycerol-3phospho-ethanolamine triethyl ammonium salt (PEG-DSPE), having PEG moieties of $350 \mathrm{Da}, 2 \mathrm{kDa}$, and $12 \mathrm{kDa}(0.35 \mathrm{~K}-$ PEG-DSPE; 2K-PEG-DSPE; 12K-PEG-DSPE, respectively), and the uncharged 3-methoxy polyethylene glycol-oxycarbonyl 3-amino-1,2-propandiol distearoyl ester having a PEG moiety of $2 \mathrm{kDa}$ (2K-PEG-DS), were from Alza Corp. (Mountain View, California). ${ }^{18}$ The uncharged 3-methoxy-polyethelene glycol 1,2-distearoyl glycerol (2K-PEG-DSG) was from NOF Corp. (Tokyo, Japan).

Human serum samples from healthy volunteer donors, obtained through an institutionally approved phlebotomy protocol, were stored at $-70^{\circ} \mathrm{C}$ until use.

\section{Preparation and characterization of liposomes and micelles}

The freeze-dried lipid components (originally dissolved in tertiary butanol) were hydrated in $10 \mathrm{~mL}$ sterile pyrogen-free normal saline (NS) by vortexing for $2-3$ minutes at $70^{\circ} \mathrm{C}$ to form multilamellar vesicles (MLVs). The MLVs were downsized through 0.4 - and $0.1-\mu \mathrm{m}$ polycarbonate filters in two steps, 10 times through each, using a 10-mL extruder barrel from Northern Lipids (Vancouver, British Collumbia, Canada) at $62^{\circ} \mathrm{C}$. Liposomes were suspended in $0.5 \mathrm{M} \mathrm{NaCl} / 5 \mathrm{mM}$ histidine buffer ( $\mathrm{pH}$ 6.5). Micelles were prepared by extensive vortex mixing of $2 \mathrm{~K}-\mathrm{PEG}-\mathrm{DS}-\mathrm{PE}$ or $2 \mathrm{~K}-\mathrm{PEG}-\mathrm{DS}$ in saline at $2 \mathrm{mg} / \mathrm{mL}$, followed by filtration through $0.22-\mu \mathrm{m}$ filters. The phospholipid concentration of preparations was determined using a modification of Bartlett's procedure. ${ }^{19}$ Particle size distribution was determined by dynamic light scattering (DLS), using an ALVNIBS/HPPS High Performance Particle Sizer with ALV-5000/ EPP multiply digital correlator (ALV-Laser Vertriebsgesellschaft $\mathrm{GmbH}$, Langen, Germany). Liposome surface potential was determined by measuring 4-heptadecyl-7hydroxycoumarin ionization over a broad range of $\mathrm{pH}$ values as described earlier. $^{20}$ Table 2 shows the essential characteristics of all preparations used.

\section{Determination of bacterial endotoxin (LPS) in liposome dispersions}

The LPS content of liposomes prepared for this study was determined by a Limulus amebocyte lysate assay (PYROGENT Plus, Cat. No. N284-06, Cambrex Bio Science Walkersville, Inc., Walkersville, Maryland), after dissolving ( $96 \%$ ethanol) and separating (ultrafiltration using $20 \mathrm{kDa}$ cutoff membrane) the lipids from LPS. ${ }^{21}$ Acceptance criterion as pyrogen-free was $\leq 0.5$ endotoxin units $(\mathrm{EU}) / \mathrm{mL}(0.01-0.25 \mathrm{ng} \mathrm{LPS} / \mathrm{mL})$.

\section{Measurement of complement activation in vitro}

Liposomes were incubated with undiluted normal human serum (NHS) in a shaking water bath, and $\mathrm{C}$ activation was estimated by measuring the formation of $\mathrm{S}$ protein-bound $\mathrm{C}$ terminal complex (SC5b-9) with an enzyme-linked immunosorbent assay (ELISA; Quidel Co., San Diego, California), as described earlier. ${ }^{22,23}$ In a typical experiment we mixed $10 \mu \mathrm{L}$ liposomes with $40 \mu \mathrm{L}$ serum in Eppendorf tubes, which were 
Table 2

Composition and physicochemical characteristics of liposomes

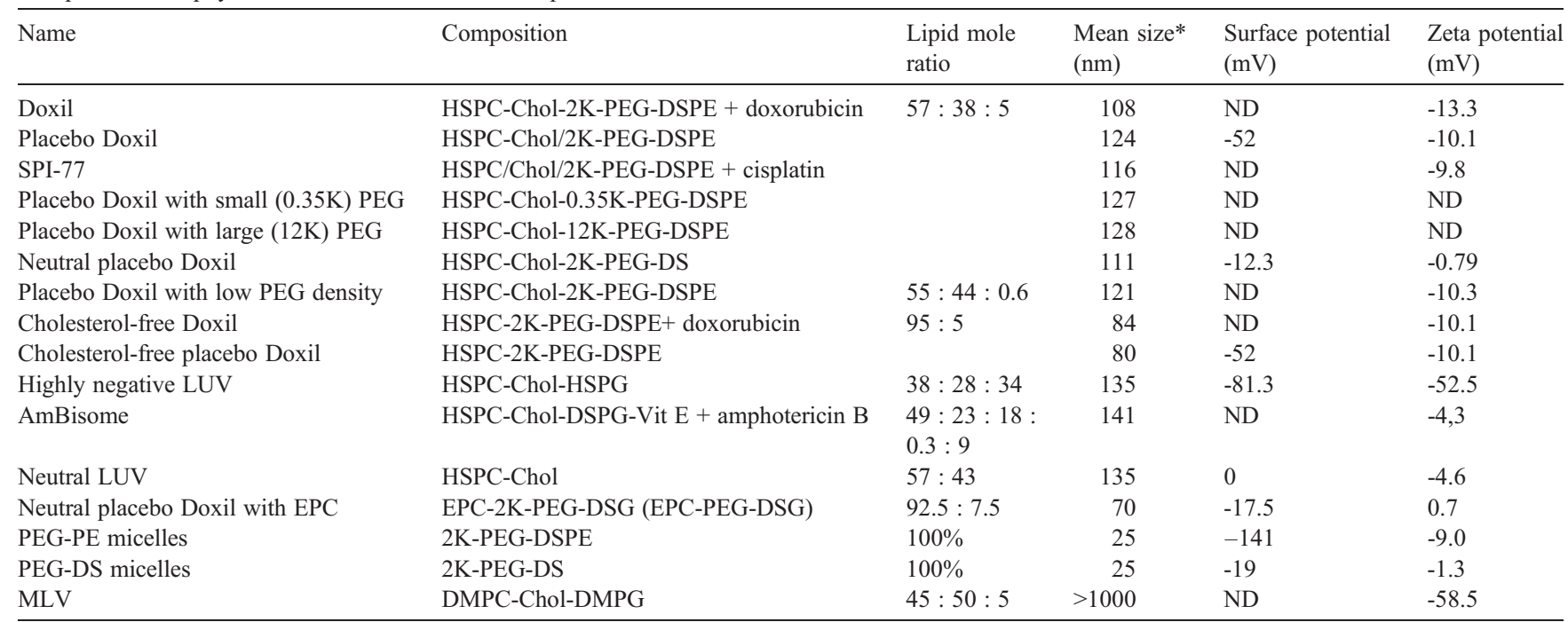

* Mean size was determined by DLS in $5 \%(\mathrm{w} / \mathrm{v})$ dextrose, triplicate measurements with $\mathrm{SD}<10 \%$. ND, not done.

then incubated for 30 minutes at $37^{\circ} \mathrm{C}$ in a shaking water bath (shaking rate of $80 \mathrm{rpm}$ ). The reaction was stopped by adding 20 volumes of $10 \mathrm{mM}$ EDTA, $25 \mathrm{mg} / \mathrm{mL}$ bovine serum albumin, $0.05 \%$ Tween 20 , and $0.01 \%$ thimerosal ( $\mathrm{pH} 7.4$ ) (i.e., the "sample diluent" of the SC5b-9 ELISA kit, supplemented with EDTA).

Morphological analysis of liposomes by differential interference contrast (DIC) and cryotransmission electron microscopy (cryo-TEM)

A light microscope with DIC (Nomarski) optics was used to examine the presence of aggregates in various liposome preparations. A small drop of the liposome stock solutions was placed in a concave well of a glass slide and covered with a coverglass. The cryo-TEM analysis of liposomes was performed by methods described earlier. ${ }^{24,25}$

\section{Animal studies}

Experiments using pigs were performed at the Uniformed Services University of the Health Sciences (USUHS) and at Semmelweis Medical University in Hungary. They were approved by the local Animal Subject Review Committees and followed their guidelines, treating the animals humanely. Swine $(25-40 \mathrm{~kg})$ of both sexes were purchased from local vendors. They were sedated with intramuscular ketamine $(500 \mathrm{mg})$ and anesthetized with $2 \%$ isoflurane, using an anesthesia machine, or with intravenous nembutal $(30 \mathrm{mg} / \mathrm{kg}$ ). A pulmonary artery catheter was advanced via the right internal jugular vein through the right atrium into the pulmonary artery to measure pulmonary artery pressure (PAP). Systemic arterial pressure (SAP) was measured in the femoral artery. Other details of surgery, instrumentation, and hemodynamic analysis were described previously. ${ }^{13,15,23}$

\section{Drug treatments}

The indicated amounts of liposomes and other test materials were diluted in phosphate buffered saline (PBS) and injected into the pulmonary artery as a bolus, via the pulmonary arterial catheter. Liposomes were flushed into the circulation with 5-10 mL PBS.

\section{Quantifying of physiological changes during liposome reactions}

Liposome reactions were quantified with the cardiac abnormality score (CAS), a semiquantitative measure of the severity of cardiac electric, circulatory (systemic and pulmonary), and skin changes during CARPA. ${ }^{26}$ Scores of 0 to 5 imply no response (CAS: 0), minimal (CAS: 1), mild (CAS: 2), moderate (CAS: 3), severe (CAS: 4), and lethal (CAS: 5) reactions. $^{26}$ The symptoms specifying different CAS values are specified in the legend to Table 3.

\section{Statistical analysis}

Data from the in vitro $\mathrm{C}$ assays are expressed as mean of triplicate determinations $\pm \mathrm{SD}$. Multiple group comparisons were done by analysis of variance followed by the Student-NeumanKeuls post-hoc test. Differences between groups were considered significant at $P<0.05$.

\section{Results}

Interindividual and interbatch variation of complement activation by Doxil and AmBisome in vitro

In previous studies we demonstrated substantial individual variation of Doxil-induced $\mathrm{C}$ activation in NHS. ${ }^{14}$ Also, in preliminary studies we found that different Doxil or Calyx batches display different capabilities to activate C in NHS. Thus, for the present dissection of liposomal structural factors 
Table 3

Cardiopulmonary responses of pigs to different liposomes

\begin{tabular}{|c|c|c|c|c|c|c|}
\hline \multirow[t]{2}{*}{ Liposome or micelle } & \multicolumn{4}{|c|}{$\begin{array}{l}\text { Bolus dose } \\
\text { (nmol phospholipid/kg) }\end{array}$} & \multicolumn{2}{|c|}{ Reaction } \\
\hline & $5-30$ & $30-150$ & $150-1000$ & $1000-10^{4}$ & CAS* & $n /$ all \\
\hline \multirow[t]{4}{*}{ Doxil } & 6 & 1 & 5 & & 0 & $1 / 19$ \\
\hline & & 1 & & & $2-3$ & $1 / 19$ \\
\hline & & 3 & & & 4 & $8 / 19$ \\
\hline & & 3 & & & 5 & $9 / 19$ \\
\hline \multirow[t]{3}{*}{ Placebo Doxil } & 1 & & 1 & & 0 & $2 / 6$ \\
\hline & & 1 & & & 2 & $1 / 6$ \\
\hline & & 3 & & & 3 & $3 / 6$ \\
\hline SPI-77 & & 2 & & & 0 & $2 / 2$ \\
\hline \multirow{2}{*}{$\begin{array}{l}\text { Placebo Doxil with } \\
\text { small (0.35K) PEG }\end{array}$} & & 2 & & & 0 & $2 / 3$ \\
\hline & & 1 & & & $2-3$ & $1 / 3$ \\
\hline \multirow{2}{*}{$\begin{array}{l}\text { Placebo Doxil with } \\
\text { large (12K) PEG }\end{array}$} & & 1 & & & 3 & $1 / 3$ \\
\hline & & 2 & & & 4 & $2 / 3$ \\
\hline \multirow[t]{2}{*}{ Neutral placebo Doxil } & & & 3 & 1 & 0 & $1 / 4$ \\
\hline & & & & & 1 & $3 / 4$ \\
\hline $\begin{array}{l}\text { Placebo Doxil with } \\
\text { low PEG density }\end{array}$ & & & 1 & & 0 & 1 \\
\hline $\begin{array}{l}\text { Cholesterol-free } \\
\text { Doxil }\end{array}$ & & 2 & & & 3 & $2 / 2$ \\
\hline \multirow{2}{*}{$\begin{array}{l}\text { Cholesterol-free } \\
\text { placebo Doxil }\end{array}$} & 2 & 1 & & & 2 & $1 / 2$ \\
\hline & & & & & 1 & $1 / 2$ \\
\hline \multirow{2}{*}{$\begin{array}{l}\text { Highly negative } \\
\text { LUV }\end{array}$} & & 3 & 2 & & $2-3$ & $3 / 5$ \\
\hline & & & & & 5 & $2 / 5$ \\
\hline \multirow[t]{2}{*}{ AmBisome } & & 5 & & & 4 & $4 / 5$ \\
\hline & & & & & 5 & $1 / 5$ \\
\hline \multirow[t]{2}{*}{ Negative EPC LUV } & 2 & & & & 4 & $2 / 4$ \\
\hline & 2 & & & & 5 & $2 / 4$ \\
\hline Neutral LUV & 1 & & 4 & 1 & 0 & $6 / 6$ \\
\hline $\begin{array}{l}\text { Neutral placebo } \\
\text { Doxil with EPC }\end{array}$ & 1 & & & & 5 & $1 / 1$ \\
\hline PEG-PE micelles & 2 & & & & 0 & $2 / 2$ \\
\hline PEG-DS micelles & 2 & & & & 0 & $2 / 2$ \\
\hline \multirow[t]{2}{*}{ MLV } & 40 & & & & 4 & $35 / 40$ \\
\hline & & & & & 5 & $8 / 40$ \\
\hline Zymosan & N/A & N/A & N/A & N/A & $4-5$ & $100 / 100$ \\
\hline
\end{tabular}

* The symptoms specifying different CAS values were as follows: CAS-1, small but significant changes in PAP or SAP with minimal or no changes in EKG and/or cardiac output $(\mathrm{CO})$ and/or partial pressure of $\mathrm{CO}_{2}\left(\mathrm{PCO}_{2}\right)$; CAS-2, noticeable rises of PAP with mild arrhythmia (tachycardia and/or bradycardia, initial rise followed by small declines in SAP, $\mathrm{CO}$, and $\mathrm{PCO}_{2}$ ); CAS-3, more expressed changes in these parameters, but not reaching physiological limits (e.g., $80 \mathrm{mmHg}$ PAP, $40 \mathrm{mmHg}$ SAP); CAS-4, massive, but still reversible changes in all variables; CAS-5, cardiac arrest with or without ventricular fibrillation, fatal unless the animal is salvaged with epinephrine, cardiac massage, or both.

contributing to $\mathrm{C}$ activation, we used a preselected highly reactive Doxil batch as the source of liposomal doxorubicin (i.e., Doxil) and a highly reactive NHS as serum source. Doxil in this serum caused significantly greater $\mathrm{C}$ activation than the equivalent empty liposomes (placebo Doxil) as well as all other tested doxorubicin-free liposomes differing in surface charge (Figure 1, $A$ ) or PEG parameters (Figure 1,B). These observations suggest that the presence of doxorubicin in liposomes was a major contributor to $\mathrm{C}$ activation. However, compared to baseline, empty liposomes were also triggers of $\mathrm{C}$ activation, and we observed small but significant differences among their activities. In

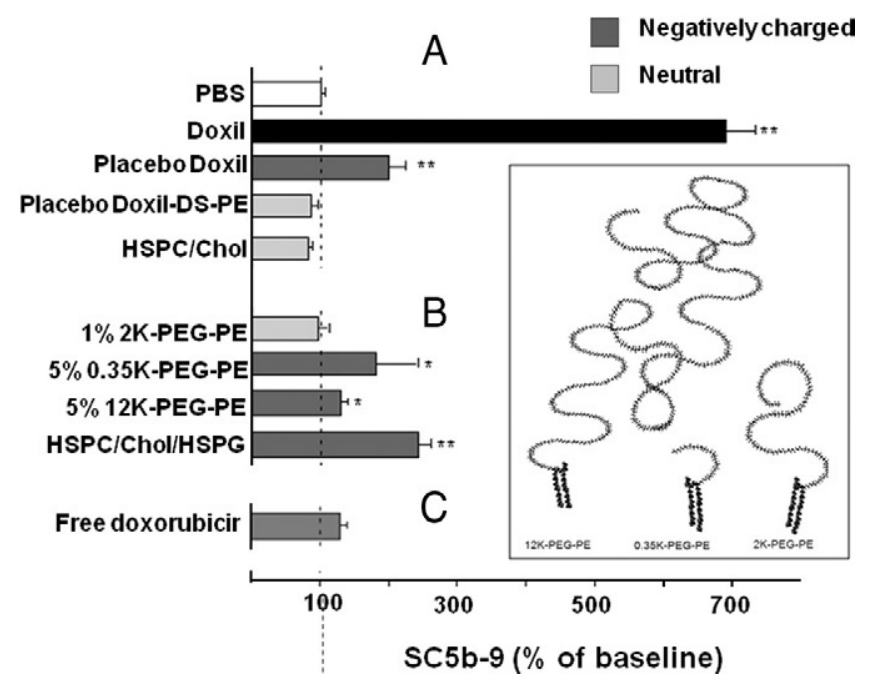

Figure 1. Complement activation by liposomes in a Doxil-sensitive normal human serum. The bars represent percentage increase of SC5b-9 over baseline after 40 minutes' incubation at $37^{\circ} \mathrm{C}$. Error bars are standard deviation (SD) for duplicate or triplicate wells. Black and gray shadings represent negative and neutral surface charges, respectively. (A) Roles of doxorubicin and surface charge. (B) Comparison of placebo Doxil with different PEG size and density. (C) An independent experiment in which 50 $\mu \mathrm{g} / \mathrm{mL}$ free doxorubicin was incubated with 20 samples of undiluted NHS as described for liposomes. The insert illustrates the size difference among the PEG-PEs used.

particular, the presence of 5\% PEG-PE on the surface, regardless of PEG chain length $(350,2000$, or $12,000 \mathrm{Da}$, Figure 1, B), slightly accelerated $\mathrm{C}$ activation compared to neutral DS-PEcontaining vesicles as well as PEG-free HSPC-Chol vesicles, or reduced (1\%) 2K-PEG-PE-containing liposomes, which were nonactivators. Figure 1, $B$ also raises the possibility that the highly extended and possibly multiply coiled 12K-PEG on DSPE (inset in Figure 1) might provide some protection against $C$ activation by phosphate diester PEG-DSPE. Consistent with the causal role of surface charge in reactivity, the strongly negative HSPC-CholHSPG caused much stronger activation than the comparable, less negative vesicles (Figure 1, $B$ ).

As for the possible contribution of free doxorubicin to $\mathrm{C}$ activation by Doxil, Figure 1, $C$ shows that incubation of $50 \mu \mathrm{g} /$ $\mathrm{mL}$ free doxorubicin with serum led to no, or minimal $\mathrm{C}$ activation. Taken together with the fact that free doxorubicin in Doxil is $<5-10 \%$ of total doxorubicin ${ }^{10}$ (i.e., $<2.5-5 \mu \mathrm{g} / \mathrm{mL}$ in serum upon incubation), it is unlikely that free doxorubicin at a dose 10 to 20 -fold (at 5-10\%) lower than the above minimally activating dose would be a major contributor to $\mathrm{C}$ activation.

Figure 2, $A$ and $B$ show further in vitro $C$ tests in NHS wherein AmBisome, a highly negatively charged (16\% DSPGcontaining) antifungal (amphotericin B-containing) liposome formulation (Figure 2,A) and three more Doxil look-alikes (Figure 2, B) were assessed for SC5b-9 production in multiple NHS, using zymosan as positive control. AmBisome turned out to be a very strong $\mathrm{C}$ activator in each of 20 tested NHS samples, whereas SPI-77, a liposomal formulation having identical lipid composition to Doxil, but passively loaded with cisplatin (also referred to as "Stealth cisplatin"), ${ }^{27}$ caused no significant C 

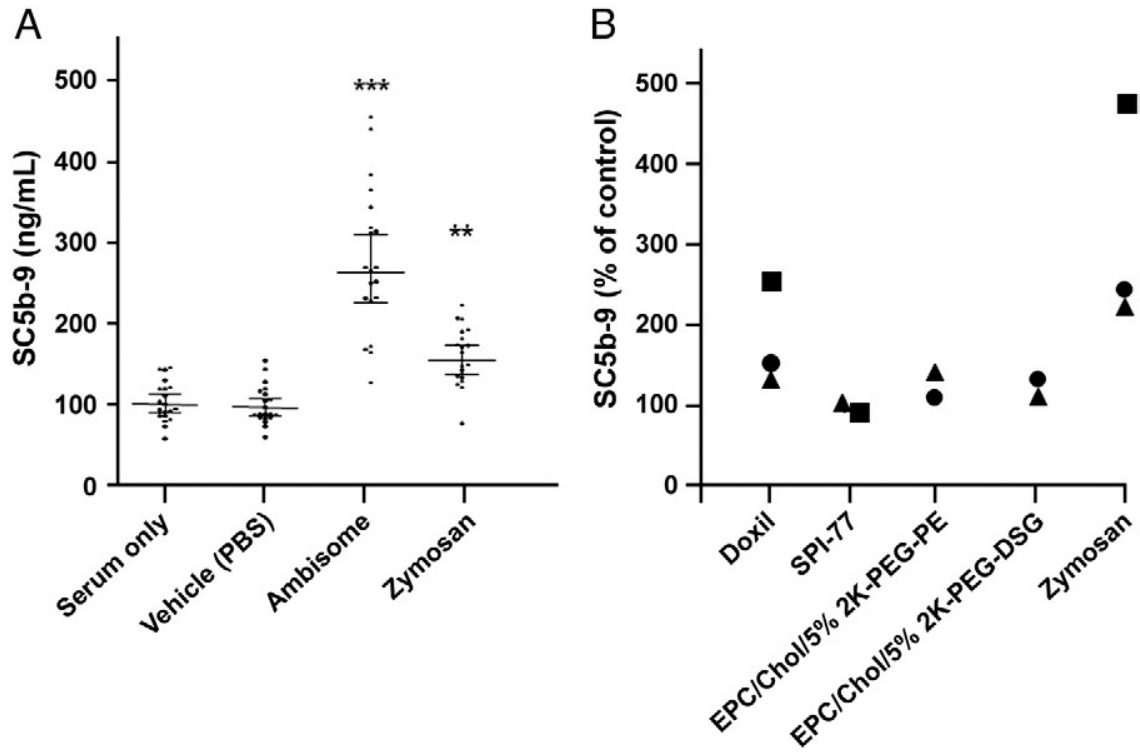

Figure 2. In vitro studies similar to those in Figure 1, showing individual data points (mean of duplicate determinations). In (B), identical symbols represent identical serum donors. (A) and (B) show different experimental series.

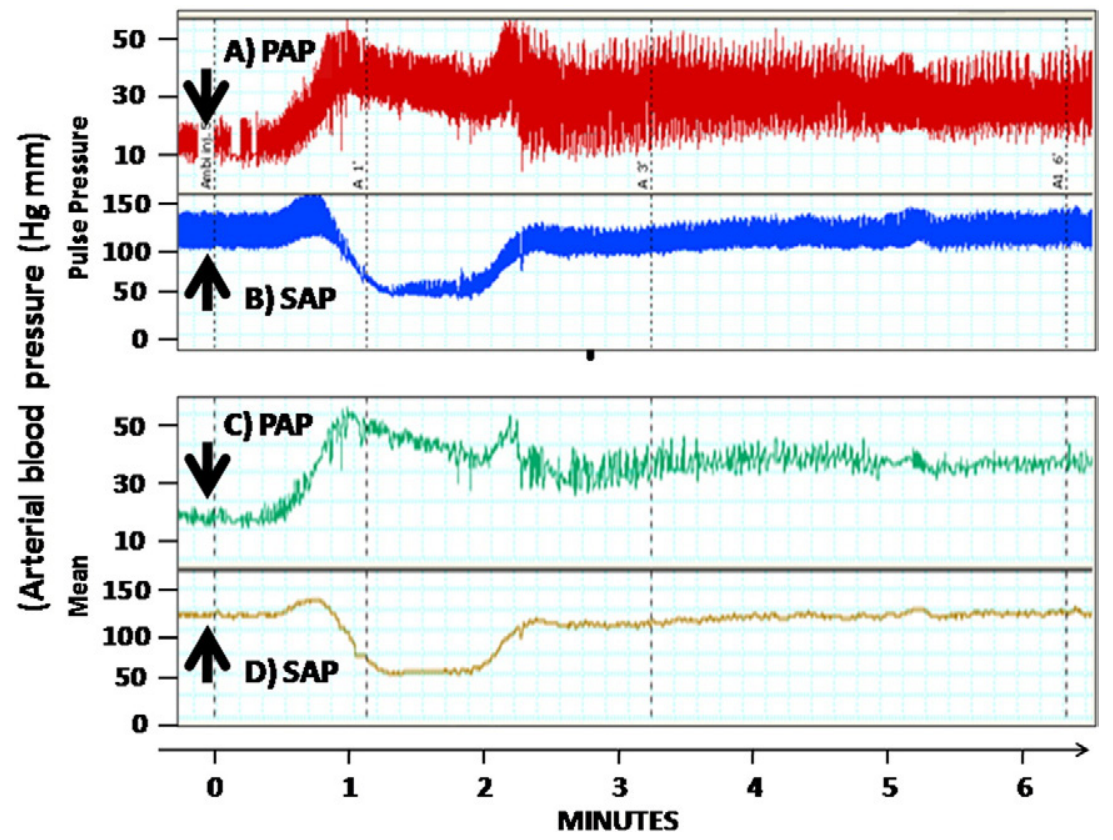

Figure 3. Cardiopulmonary changes following bolus administration of AmBisome ( $0.01 \mathrm{mg} / \mathrm{kg}, 80 \mathrm{nmol}$ phospholipid/kg) in a pig (typical out of five). Upper panels are real-time recordings showing the pulse amplitude; lower panels show averaged blood pressure values. The arrow shows the moment of liposome administration.

activation. Nor did EPC containing 5 mol\% 2K-PEG-DSPE and EPC containing $5 \mathrm{~mol} \%$ uncharged $2 \mathrm{~K}-\mathrm{PEG}-\mathrm{DSG}$. These observations provide further examples for the strong reactogenicity of PG when applied in relatively high amounts. Of note, the effect of free amphotericin B could not be tested due to its low water solubility.

In a further experiment we looked at the C-activating effects of 2K-PEG-PE micelles in two Doxil-reactive sera and found no apparent rise of SC5b-9 (data not shown), at least at concentrations corresponding to the amount of PEG-PE in Doxil $(3.2 \mathrm{mg} / \mathrm{mL})$.

\section{In vivo reactogenicity of different liposomes in pigs}

Depending on type, dose, and administration schedule, liposomes can trigger massive hemodynamic and cardiopulmonary changes in pigs. The reaction is illustrated for AmBisome in Figure 3, whose bolus injection at $0.01 \mathrm{mg} / \mathrm{kg}$ caused greater 

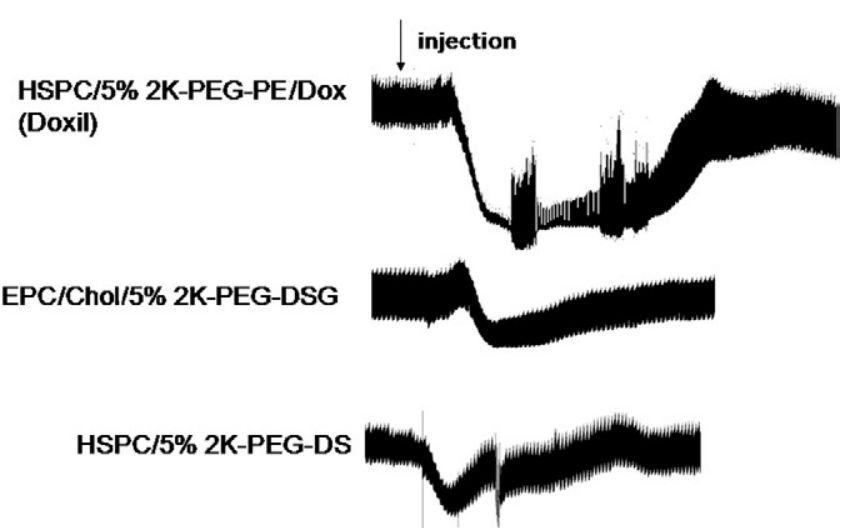

Figure 4. Continuous records of systemic arterial pressure (SAP) changes caused by bolus injection of Doxil and two of its doxorubicin-free neutral derivatives. Illustration of the minimal reactogenicity of PEGylated neutral LUVs. These test agents were administered to different pigs as first bolus.

than threefold (or $>300 \%$ ) rise of PAP and some $60 \%$ decline of SAP within 1 minute. Steady state resumed within 3 minutes, at supranormal for PAP and physiological pressure for SAP. Such moderate to severe reactions occurred in all of five AmBisomeinjected pigs (Table 3) and all other pigs where, in Table 3, "cardiopulmonary abnormality scores" (CAS) $>3$ are shown. As detailed in the Methods and Table 3, CAS is a composite measure of CARPA, derived from grouping the symptoms of mild, moderate, severe, and lethal reactions. ${ }^{26}$

Table 3 presents the dose dependence, frequency, and grade of cardiopulmonary response of pigs to different liposomes, using CAS as end point. Consistent with the in vitro SC5b-9 measurements, AmBisome, Doxil, and zymosan caused the strongest, mostly severe or lethal (CAS 4-5) reactions, whereas SPI-77, despite its identical size distribution and lipid composition to Doxil, ${ }^{27}$ caused neither $\mathrm{C}$ activation in serum nor reaction in pigs. Although minimal to mild reactions did occur with liposomes that caused no apparent rise of SC5b-9 in NHS (e.g., EPC-Chol having 5 mol\% 2K-PEG-DSG and HSPC having $5 \mathrm{~mol} \%$ 2K-PEG-DS) (Figure 4), considering the mentioned individual variation of in vitro $\mathrm{C}$ response to liposomes, it cannot be excluded that a larger number of serum tests would have revealed the C-activating capability of those liposomes as well. This implies that the pig model is more sensitive than the in vitro assay in revealing acute immune reactivity.

\section{The shape of liposomes is modified by doxorubucin remote loading}

Figure 5, $A$ shows that those liposomes in Doxil wherein the doxorubicin sulfate crystal "disks" are relatively "thick" are also elongated. These liposomes have oval, coffee beanlike shape in contrast to the spherical shape of vesicles with no or "thin" disks. This suggests that the disks, if their physical measures exceed the space available within the aqueous phase of liposomes, elongate the vesicles in one direction. In support of this concept, the shapes of SPI-77
(Figure 5, B) and placebo Doxil (Figure 5, C) liposomes were highly symmetrical and spherical. Considering that the equatorial belt of oval particles have, along their longer axis, lower curvature than that of corresponding spheres, the ovaliform transition of Doxil liposomes implies an increase of flat surface area, at least in one dimension. In addition to the above shape change of individual liposomes, DIC microscopy in a C-reactive commercial Doxil vial revealed the presence of multimicron aggregates, with intercalated red material that corresponds to extravesicular doxorubicin (Figure $5, D-F)$. These aggregates have in all dimensions large, nonsmooth surfaces that are partially covered by extravesicular doxorubicin, another major increase of blood-exposed flat liposome surface. Although at this stage we do not have quantitative assessment of doxorubicin-induced shape changes and related surface expansion in Doxil, these morphological observations highlight at least two possibilities for membrane structural changes caused by doxorubicin that may account for increased $\mathrm{C}$ activation.

\section{Discussion}

The main goal of this study was to explore yet unknown structural factors in liposomes that might influence their Cactivating and anaphylactogenic potentials. The clinical relevance of the subject lies in the increased risk for non-IgEmediated infusion reactions in patients treated for the first time with many liposomal drugs, including Doxil, AmBisome, Abelcet, Amphocyl, and Daunoxome. ${ }^{10-12,14,16,28-36}$ Although slow initial infusion and premedication with corticosteroids and antihistamines are effective in reducing the frequency of CARPA, ${ }^{37}$ reactions still occur in up to $10 \%$ of patients treated with Doxil despite slow infusion and/or premedication. ${ }^{10}$

The present study focused primarily on $\mathrm{C}$ activation and in vivo reactogenicity of Doxil, the first liposomal nanomedicine, which has been for many years successfully used in cancer chemotherapy. ${ }^{6,7,28-33,38}$ Initially it was thought that steric stabilization with PEG should protect against $\mathrm{C}$ binding to liposomes ${ }^{39}$; however, more recent studies proved that Doxil is a strong $\mathrm{C}$ activator, ${ }^{14,37}$ partly as a consequence of the net anionic charge of the phosphate moiety on $2 \mathrm{~K}-\mathrm{PEG}-\mathrm{PE} .{ }^{17}$

To explore further structural features of Doxil that might contribute to $\mathrm{C}$ activation, here we performed head-to-head comparison of $\mathrm{C}$ activation and in vivo reactogenicity of commercial Doxil and equivalent drug-free vesicles, differing from Doxil and from each other in one feature at a time. These features were surface charge, PEG phospholipid anchor charge, PEG size and density, and particle lipid composition and structure. We also studied the role of liposomal payload by comparing Doxil with placebo Doxil and Stealth cisplatin, which are identical to Doxil in lipid composition and size but differ in their payload. The role of net surface charge was assessed by testing HSPG-containing (strongly negative) liposomes and AmBisome, whereas the influence of PEG phospholipid anchor charge was tested using uncharged PEG-DS and PEG-DSG. The surface density of PEG was assessed by comparing the effects of $0.6 \%$ (when the PEG is in the mushroom conformation) ${ }^{40}$ with 

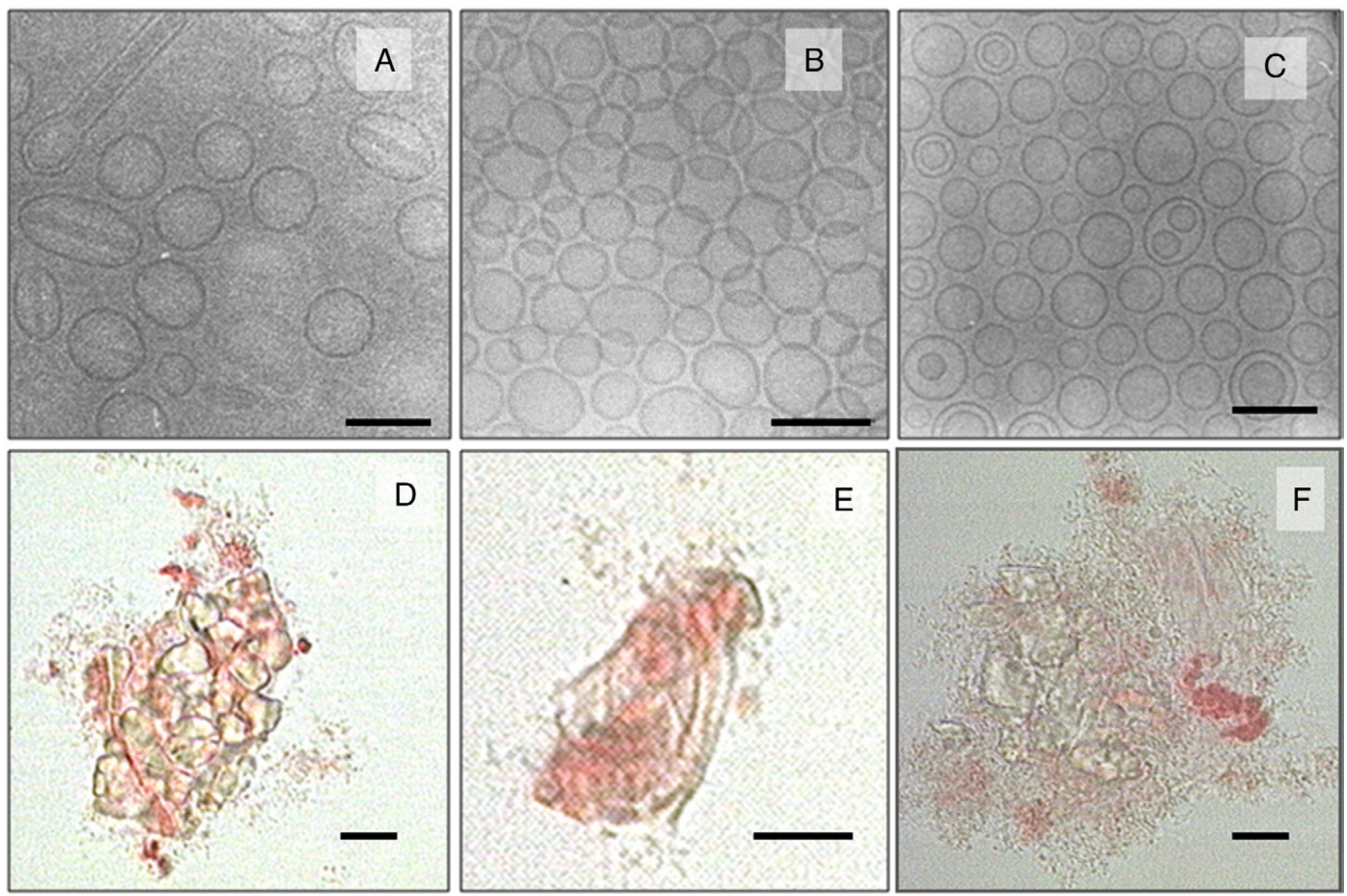

Figure 5. Cryo-TEM images of (A) Doxil; (B) SPI-77 (equivalent liposomes with cisplatin payload), and (C) placebo Doxil (i.e., Doxil without doxorubicin). (D-F) DIC microscopy of Doxil aggregates with doxorubicin seen as red gluelike material intercalated among the vesicles. Bars are $100 \mathrm{~nm}$.

5\% 2K-PEG-PE (when the PEG is in a transition between the mushroom and brush conformations). ${ }^{40}$ The role of PEG chain length was established by comparing Doxil-like large unilamellar vesicles (LUVs) prepared with $2 \mathrm{~K}-, 0.35 \mathrm{~K}$-, and $12 \mathrm{~K}-\mathrm{PEG}-$ $\mathrm{PE}$. Finally, to explore the impact of particle structure, lipopolymer micelles with different head group (2K-PEGDSPE，2K-PEG-DS，2K-PEG-DSPG，2K-PEG-EPG) were tested. As positive controls for liposome-induced $\mathrm{C}$ activation and cardiopulmonary reactions we used multilamellar DMPCChol-DMPG liposomes (MLVs) and zymosan, which were shown earlier to be potent $\mathrm{C}$ activators and CARPA inducers in pigs. $^{13-16}$

Analysis of the effects of the above vesicle parameters in a Doxil-sensitive NHS showed major and minor impacts. The two liposome variables that led to major increases in $\mathrm{C}$ activation were the presence of doxorubicin and expressed net negative surface charge on vesicles, whereas all other listed permutations of surface properties caused minor impact on SC5b-9 formation. The massive C-activating effect of Doxil, just like that of AmBisome, could not be explained by LPS contamination, as these commercial formulations are considered pyrogen-free. Likewise, the strong C-activating effect of (negatively charged) drug-free liposomes is hardly explainable by endotoxin contamination because, upon their preparation, they had $\leq 0.5 \mathrm{EU} / \mathrm{mL}$ LPS $(\leq 0.01-0.25 \mathrm{ng} \mathrm{LPS} / \mathrm{mL}$ ), which is six to eight orders of magnitude lower than the reported minimum concentration of LPS $(200-500 \mu \mathrm{g} / \mathrm{mL}),{ }^{41,42}$ causing short-term (within 1 hour) $\mathrm{C}$ activation in human plasma or serum. Nevertheless, in light of the fact that our assays were not run aseptically, and that nanoparticles can enhance the immunostimulatory properties of endotoxin, ${ }^{43,44}$ some minor influence of LPS on the changes we observed cannot a priori be ruled out.

The finding that doxorubicin-containing liposomes led to significant increase of SC5b-9 formation, whereas free doxorubicin was probably not a contributor to this effect, suggests that doxorubicin's action might be indirect, via modifying the surface of liposomes. According to our electron microscopic analysis, one potential Doxil-specific surface alteration might arise from the presence of elongated doxorubicin crystals in the aqueous space of Doxil, forcing an ovaliform transition of spherical vesicles with an increase in the ratio of flat vs. highly curved areas on the bilayer surface. The other Doxil-specific surface effect was the formation of multimicron aggregates that yield large, flat, incongruent surfaces. The coffee-bean, or American football-like oval appearance of Doxil is widely documented in the literature; what our presented cryo-TEM images highlight for the first 
time to our knowledge is that this shape change may be related to the length and bulkiness of doxorubicin crystals within liposomes. Considering that $\mathrm{C}$ activation proceeds on membrane surfaces whose curvature is an important factor ${ }^{45}$ in determining the buildup of multimolecular complexes, such as the $\mathrm{C} 3$ convertases $(\mathrm{C} 4 \mathrm{~b} 2 \mathrm{~b}$ or $\mathrm{C} 3 \mathrm{bBb})$ and $\mathrm{C} 5$ convertases (C4b2b3b or $\mathrm{C} 3 \mathrm{bBb} 3 \mathrm{~b})$, the low-curvature parts in the case of oval Doxil vesicles, together with the visibly large, incongruent surfaces on aggregates, may explain, at least in part, the increased reactogenicity of Doxil.

The $\mathrm{C}$ activation-promoting activity of negative surface charges on liposomes is a well-established phenomenon. ${ }^{12,22}$ What is new information in the present study is that AmBisome causes massive C activation in NHS essentially without individual variation (strong activation was present in all of 20 tested NHS samples). In this aspect, AmBisome significantly differs from Doxil, in that the latter causes strong $C$ activation only in certain sensitive sera, which phenomenon also shows some interbatch variation most likely as a consequence of variable storage time (data not shown).

As for the impact of particle type, our limited analysis in the present study showed neither $\mathrm{C}$ activation, nor reactivity in pigs of anionic micelles formed from PEG-DSPE and its noncharged modifications. However, it is not clear if this is due to the small size of the micelles or the fact that their PEG chains are densely packed in a brush conformation that is highly extended and prevents interaction with proteins at the micellar lipid/water interface. Thus, unlike mixed-lipid micelles of Cremophor EL, which are strong $\mathrm{C}$ activators, ${ }^{22,46}$ the better defined PEG-DSPE micelles may be free from such side effects. One possible explanation is a lack of ready fusion with lipoproteins to form large particles, as the surface of 10 to $20 \mathrm{~nm}$ individual micelles is too small to accommodate direct deposition of $\mathrm{C}$ convertases. ${ }^{46}$

In conclusion, this study showed that for nanoliposomes the choice of PC, the carbon chain length, and surface density of PEG-PE have minor or no effect, whereas liposomal surface charge and the presence of a shape-modifying drug, such as doxorubicin, are major contributors to liposome-induced $\mathrm{C}$ activation and related HSRs. Attention to these correlations and appropriate optimization of vesicle parameters might help in reducing the risk of infusion reactions to liposomal drugs.

\section{References}

1. Goyal P, Goyal K, Gurusamy S, Kumar V, Singh A, Katare Opnath Mishra DN. Liposomal drug delivery systems-clinical applications. Acta Pharm 2005;55:1-25.

2. Immordino ML, Dosio F, Cattel L. Stealth liposomes: review of the basic science, rationale, and clinical applications, existing and potential. Int J Nanomedicine 2006;1:297-315.

3. De Jong WH, Borm PJ. Drug delivery and nanoparticles: applications and hazards. Int J Nanomedicine 2008;3:133-49.

4. Torchilin V. Antibody-modified liposomes for cancer chemotherapy. Expert Opin Drug Deliv 2008;5:1003-25.

5. Marcato PD, Durán N. New aspects of nanopharmaceutical delivery systems. J Nanosci Nanotechnol 2008;8:2216-29.

6. Gabizon A, Goren D, Cohen R, Barenholz Y. Development of liposomal anthracyclines: from basics to clinical applications. J Control Release 1998;53:275-9.
7. Amselem S, Gabizon A, Barenholz Y. Optimization and upscaling of doxorubicin-containing liposomes for clinical use. J Pharm Sci 2006;79:1045-52.

8. Walsh TJ, Finberg RW, Arndt C, Hiemenz J, Schwartz C, Bodensteiner $\mathrm{D}$, et al. Liposomal amphotericin B for empirical therapy in patients with persistent fever and neutropenia. N Engl J Med 1999;340:764-71.

9. Wingard JR, White MH, Anaissie E, Raffalli J, Goodman J, Arietta A, et al. A randomized, double-blind comparative trial evaluating the safety of liposomal amphotericin B versus amphotericin B lipid complex in the empirical treatment of febrile neutropenia. Clin Infect Dis 2000;31:1155-63.

10. Doxil. Package label. Available from: http://www.Doxil.com.

11. Ambisome. Package label. Available from: http://www.ambisome.com.

12. Szebeni J. The interaction of liposomes with the complement system. Crit Rev Ther Drug Carrier Syst 1998;15:57-88.

13. Szebeni J, Baranyi B, Savay S, Bodo M, Morse DS, Basta M, et al. Liposome-induced pulmonary hypertension: properties and mechanism of a complement-mediated pseudoallergic reaction. Am J Physiol 2000;279:H1319-28.

14. Szebeni J, Baranyi B, Savay S, Lutz LU, Jelezarova E, Bunger R. The role of complement activation in hypersensitivity to pegylated liposomal doxorubicin (Doxil). J Liposome Res 2000;10:347-61.

15. Szebeni J, Fontana JL, Wassef NM, Mongan PD, Morse DS, Dobbins $\mathrm{DE}$, et al. Hemodynamic changes induced by liposomes and liposomeencapsulated hemoglobin in pigs: a model for pseudo-allergic cardiopulmonary reactions to liposomes. Role of complement and inhibition by soluble CR1 and anti-C5a antibody. Circulation 1999;99:2302-9.

16. Szebeni J. Complement activation-related pseudoallergy: a new class of drug-induced immune toxicity. Toxicology 2005;216:106-21.

17. Moghimi SM, Hamad I, Andresen TL, Jörgensen K, Szebeni J. Methylation of the phosphate oxygen moiety of phospholipid-methoxy (polyethylene glycol) conjugate prevents PEGylated liposome-mediated complement activation and anaphylatoxin production. FASEB J 2006;20:2591-3

18. Priev A, Zalipsky S, Cohen R, Barenholz Y. Determination of critical micelle concentration of lipopolymers and other amphiphiles: comparison of sound velocity and fluorescent measurements. Langmuir 2002;18:612-7.

19. Shmeeda H, Even Chen S, Honen R, Cohen R, Weintraub C, Barenholz Y. Enzymatic assays for quality control and pharmacokinetics of liposome formulations: comparison with nonenzymatic conventional methodologies. Methods Enzymol 2003;367:272-92.

20. Zuidam NJ, Barenholz Y. Electrostatic parameters of cationic liposomes commonly used for gene delivery as determined by 7-heptadecyl-4hydroxycoumarin. Biochim Biophys Acta 1997;1329:211-22.

21. Schmidtgen M, Brandl M. Detection of lipopolysaccharides in phospholipids and liposomes using the limulus test. J Liposome Res 1995;5:109-16.

22. Szebeni J, Muggia FM, Alving CR. Complement activation by Cremophor EL as a possible contributor to hypersensitivity to paclitaxel: an in vitro study. J Natl Cancer Inst 1998;90:300-6.

23. Szebeni J, Baranyi L, Savay S, Milosevits J, Bodo M, Bunger R, et al. The interaction of liposomes with the complement system: in vitro and in vivo assays. Methods Enzymol 2003;373:136-54.

24. Bellare JR, Davis HT, Scriven LE, Talmon Y. Controlled environment vitrification system: an improved sample preparation technique. J Electron Microsc Tech 1988;10:87-111.

25. Talmon Y. Cryogenic temperature transmission electron microscopy in the study of surfactant systems. In: Binks BP, editor. Modern characterization methods of surfactant systems. New York: Marcel Dekker; 1999. p. 147-78.

26. Szebeni J, Baranyi L, Sávay S, Bodó M, Milosevits J, Alving CR, et al. Complement activation-related cardiac anaphylaxis in pigs: role of C5a anaphylatoxin and adenosine in liposome-induced abnormalities in ECG and heart function. Am J Physiol 2006;290:H1050-8. 
27. Peleg-Shulman T, Gibson D, Cohen R, Abra R, Barenholz Y. Characterization of sterically stabilized cisplatin liposomes by nuclear magnetic resonance. Biochim Biophys Acta 2001;1510:278-91.

28. Dezube BJ. Safety assessment: Doxil ${ }^{\mathrm{R}}$ (doxorubicin $\mathrm{HCl}$ liposome injection) in refractory AIDS-related Kaposi's sarcoma. In: Alberts DS, Garcia DJ, editors. Doxil clinical series, Vol. 1. Califon, New Jersey: Gardiner-Caldwell SynerMed; 1996. p. 1-8.

29. Gabizon A, Isacson R, Libson E, Kaufman B, Uziely B, Catane R, et al. Clinical studies of liposome-encapsulated doxorubicin. Acta Oncol 1994;33:779-86.

30. Hubert A, Lyass O, Pode D, Gabizon A. Doxil (Caelyx): an exploratory study with pharmacokinetics in patients with hormone-refractory prostate cancer. Anticancer Drugs 2000;11:123-7.

31. Skubitz KM, Skubitz AP. Mechanism of transient dyspnea induced by pegylated-liposomal doxorubicin (Doxil). Anticancer Drugs 1998;9:45-50.

32. Gabizon A, Catane R, Uziely B, Kaufman B, Safra T, Cohen R, et al. Prolonged circulation time and enhanced accumulation in malignant exudates of doxorubicin encapsulated in polyethylene-glycol coated liposomes. Cancer Res 1994;54:987-92.

33. Alberts DS, Garcia DJ. Safety aspects of pegylated liposomal doxorubicin in patients with cancer. Drugs 1997;54(Suppl 4):30-45.

34. Lyass O, Hubert A, Gabizon AA, Phase I. study of Doxil-cisplatin combination chemotherapy in patients with advanced malignancies. Clin Cancer Res 2001;7:3040-6.

35. Lenz HJ. Management and preparedness for infusion and hypersensitivity reactions. Oncologist 2007;12:601-9.

36. Gabizon AA. Pegylated liposomal doxorubicin: metamorphosis of an old drug into a new form of chemotherapy. Cancer Invest 2001;19: 424-36.

37. Chanan-Khan A, Szebeni J, Savay S, Liebes L, Rafique NM, Alving CR, et al. Complement activation following first exposure to pegylated liposomal doxorubicin (Doxil): possible role in hypersensitivity reactions. Ann Oncol 2003;14:1430-7.

38. Szebeni J, Baranyi L, Savay S, Milosevits J, Bunger R, Laverman P, et al. Role of complement activation in hypersensitivity reactions to Doxil and HYNIC-PEG liposomes: experimental and clinical studies. J Liposome Res 2002;12:165-72.

39. Utkhede DR, Tilcock CP. Studies upon the toxicity of polyethylene glycol coated lipid vesicles: acute hemodynamic effects, pyrogenicity and complement activation. J Liposome Res 1998;8:537-50.

40. Garbuzenko O, Barenholz Y, Priev A. Effect of grafted PEG on liposome size and on compressibility and packing of lipid bilayer. Chem Phys Lipids 2005; 135:117-29.

41. Roeise O, Garred P, Mollnes TE, Aasen AO. Studies on the dose dependence of endotoxin-induced in vitro activation of the complement system. Eur Surg Res 1989;21:34-42.

42. Szebeni J, Wassef N, Spielberg H, Rudolph AS, Alving CR. Complement activation by liposome-encapsulated hemoglobin in vitro. The role of endotoxin contamination. Artif Cells Blood Substit Immobil Biotechnol 1995;23:355-63.

43. Inoue K, Takano H. Aggravating impact of nanoparticles on immunemediated pulmonary inflammation. Sci World J 2011;11:382-90.

44. Shin JA, Lee EJ, Seo SM, Kim HS, Kang JL, Park EM. Nanosized titanium dioxide enhanced inflammatory responses in the septic brain of mouse. Neuroscience 2010;165:445-54.

45. Pedersen MB, Zhou X, Larsen EK, Sørensen US, Kjems J, Nygaard JV, et al. Curvature of synthetic and natural surfaces is an important target feature in classical pathway complement activation. J Immunol 2010;184:1931-45.

46. Szebeni J, Alving CR, Savay S, Barenholz Y, Priev A, Danino D, et al. Formation of complement-activating particles in aqueous solutions of Taxol: possible role in hypersensitivity reactions. Int Immunopharmacol 2001;1:721-35. 
Nanomedicine: Nanotechnology, Biology, and Medicine xx (2011) xxx nanomedicine

Nanotechnology, Biology, and Medicine

\section{Graphical Abstract}

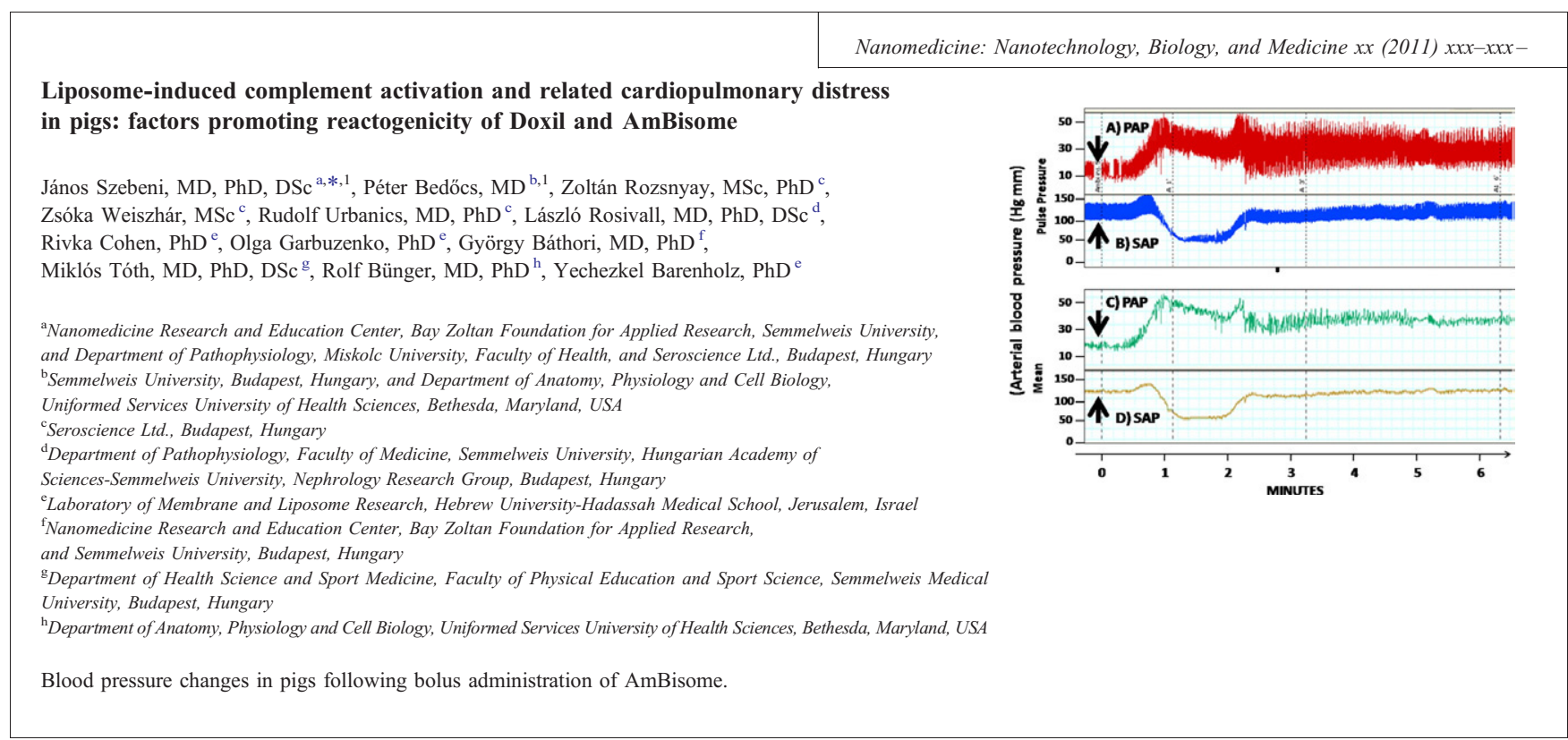

